\title{
CORRECTION
}

\section{Correction: ApoE2 Exaggerates PTSD-Related Behavioral, Cognitive, and Neuroendocrine Alterations}

Lance A Johnson ${ }^{1}$, Damian G Zuloaga ${ }^{1}$, Erin Bidiman ${ }^{1}$, Tessa Marzulla ${ }^{1}$, Sydney Weber ${ }^{1}$, Helane Wahbeh ${ }^{2}$ and Jacob Raber ${ }^{1,2,3}$

Neuropsychopharmacology (2019) 44:654; https://doi.org/10.1038/s41386-018-0261-z

Correction to: Neuropsychopharmacology; https://doi.org/10.1038/ npp.2015.95; published online 6 May 2015

Following the publication of this article the authors noted an error in Fig. 4. In sub-panels D-F, the y-axis should read "apoE (ng/ mg protein)" as opposed to "apoE (ng/ml)". The authors apologize for any inconvenience caused. The correct version of figure 4 is shown below. a

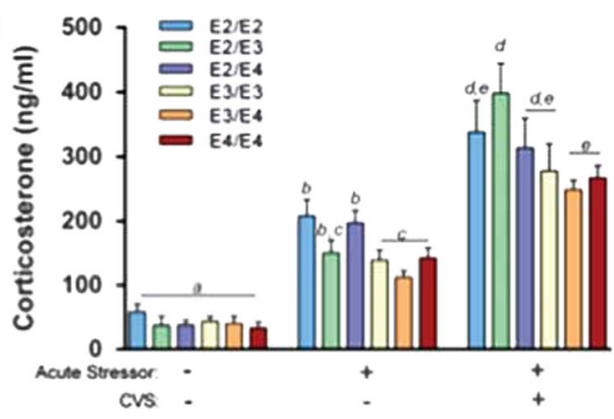

c

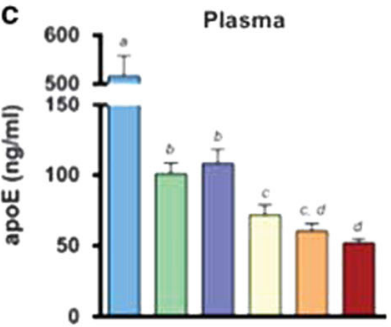

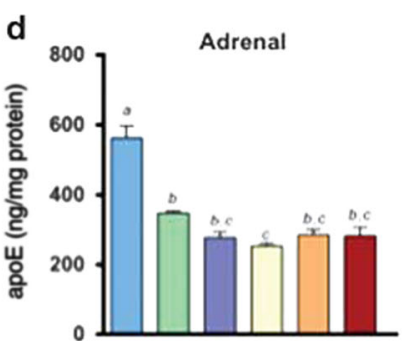
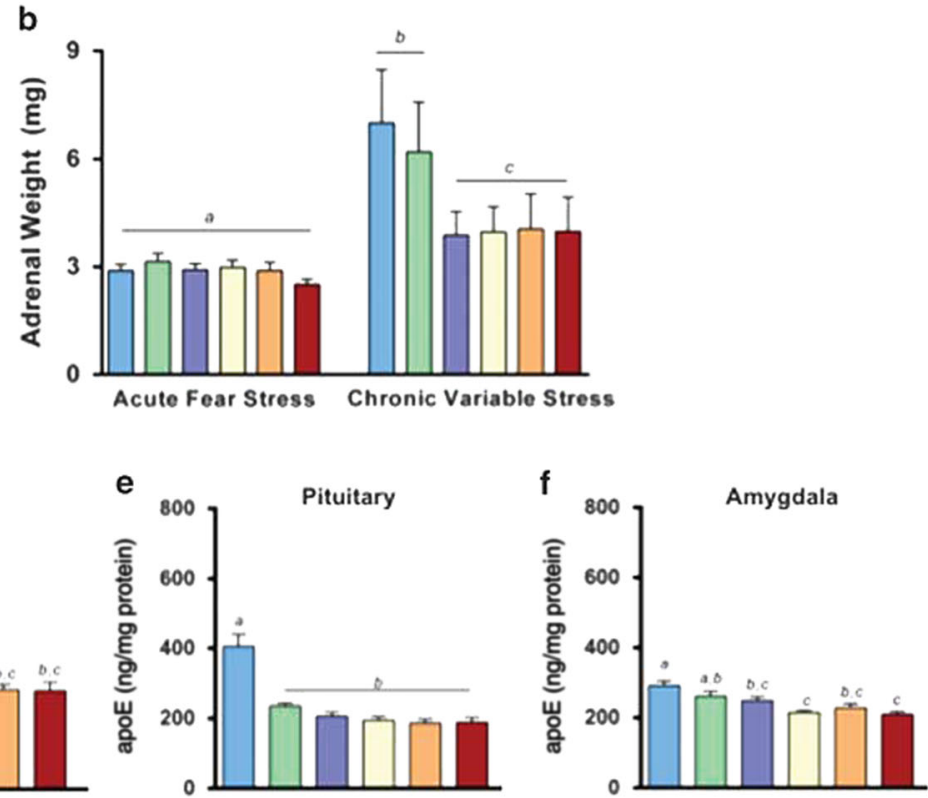

Fig. 4

'Department of Behavioral Neuroscience, Oregon Health and Science University, Portland, OR, USA; ${ }^{2}$ Department of Neurology, Oregon Health and Science University, Portland, OR, USA and ${ }^{3}$ Department of Radiation Medicine and Division of Neuroscience, ONPRC, Oregon Health and Science University, Beaverton, OR, USA

Correspondence: Jacob Raber (raberj@ohsu.edu)

Published online: 20 November 2018 